\title{
All the existences that there are
}

\author{
Alberto Voltolini \\ University of Turin \\ BIBLID [0873-626X (2012) 32; pp. 361-383]
}

\begin{abstract}
In this paper, I will defend the claim that there are three existence properties: the second-order property of being instantiated, a substantive first-order property (or better a group of such properties) and a formal, hence universal, first-order property. I will first try to show what these properties are and why we need all of them for ontological purposes. Moreover, I will try to show why a Meinong-like option that positively endorses both the former and the latter first-order property is the correct view in ontology. Finally, I will add some methodological remarks as to why this debate has to be articulated from the point of view of reality, i.e., by speaking of properties, rather than from the point of view of language, i.e., by speaking of predicates (for such properties).
\end{abstract}

\section{Keywords}

Existence, Meinongianism, subsistence, instantiation, ontological disagreement.

\section{Introduction $^{*}$}

There is a longstanding debate in philosophy concerning whether existence has to be taken either as a first-order or as a second-order property. In a stream ideally tracing Meinong (1960) back to Plato, existence is a substantive property of individuals. Yet (following perhaps Kant) Frege $\left(1974^{2}\right)$ and Russell (1905) have maintained that existence is a second-order property, a property of properties: the

* Previous versions of this paper have presented in different occasions: at the Light Entities, Real Entities colloquium at IHPST, June 27, 2009, Paris; at one of the Friday seminars at the Department of Philosophy, University of Parma, November 6, 2009, Parma; at the conference Word and Object, 50 Years Later, Department of Philosophy, University of Rome "La Sapienza”, May 28-29 2010, Rome. I thank all the participants to those happenings, especially Francesco Berto, Andrea Bianchi, Andrea Borghini, and Friederike Moltmann, for their stimulating comments.

Disputatio, Vol. IV, No. 32, May 2012 
property for a property of being instantiated. In the nominalistic alternative formulation due to Quine (1952), to be is to be the value of a (bound) variable. ${ }^{1}$ For most of the past century, in analytic philosophy the second option has been the received view. Yet Meinong's recent resurrection in some analytic quarters (from Parsons 1980 and Routley 1980 down to Castañeda 1989, Rapaport 1979, and Zalta 1983) has put this into doubt, thus reviving the first option.

Up to now, most of this debate has consisted in either party's putting forward its own thesis while criticizing the opponent's one. ${ }^{2}$ Yet this theoretical opposition is rather artefactual, for the two options are quite reconcilable. In order to properly account for existential matters, we need both the substantive first-order property (or better a group of such properties) and the second-order property. To be sure, there already have been attempts at reconciling those apparently opposite perspectives - Geach 1968, Hintikka 1986. Yet I will also hold that for the above purposes we need a third property; namely, another first-order property is formal, hence universal - all individuals possess it. In this respect, I will here defend an existential syncretism.

In what follows, I will first try to show what these properties are and why we need all of them for ontological purposes. Moreover, I will try to show why a Meinong-like option that positively endorses both the former and the latter first-order property is the correct view in ontology. Finally, I will add some methodological remarks as to why this debate has to be articulated from the point of view of reality, i.e., by speaking of properties, rather than from the point of view of language, i.e., by speaking of predicates (for such properties).

\footnotetext{
${ }^{1}$ It is not clear whether Kant really maintained a second-order conception of existence. For powerful doubts about this, cf. Berto 2010. To be sure, as Sluga (1980: 90) has reminded us, remnants of a first-order conception of existence can be found in Frege as well. As to Russell, not only in his early period he defended a first-order conception - cf. Russell $1937^{2}$ - but one can also find in that period traces of a syncretist position like the one I am defending here. Cf. on this Makin (2000: 56-57).

${ }^{2}$ For traditional and recent criticisms against existence as a first-order property cf. e.g. Frege 1979 and Williams 1992. For updated powerful criticisms to the Frege-Russell conception cf. McGinn 2000.
} 


\section{Three existence properties}

The first two existence properties I want to be committed to are those mobilized in the traditional debate on existence. First of all, I accept the second-order property typically expressed by the particular quantifier: in philosophical jargon, the property of being instantiated any property may possess.

In this respect, two caveats are immediately in order. First, not everyone committed to the idea that existence is captured by the particular quantifier takes the quantifier as typically expressing a (second-order) property, as Frege $\left(1980^{3}\right.$ a) believed. ${ }^{3}$ For one, in adhering to that idea by claiming that to be is to be the value of a variable, Quine (1952) sticked to a nominalist, property-less interpretation of such an ideia. ${ }^{4}$ Yet as a matter of fact, particularly quantified sentences can figure as LHS of biconditionals of the kind 'there is a F iff the property of being F is instantiated', what Schiffer (2003) would call '“something from nothing”- transformations'. As the RHS of those biconditionals is committed to second-order properties, it is hard to deny that the same holds of the LHS of such biconditionals.

Second, I prefer to call the quantifier 'particular' rather than 'existential', for (as we will soon see) to call it existential already prejudges the question of which is the domain the variables which it bounds range over. ${ }^{5}$

These caveats notwithstanding, the property this quantifier typically expresses clearly has an existential role. For when expressing such second-order property, that quantifier is mobilized in ontological questions, both aposteriori ('are there chimeras, fountains of youth, unicorns ... ?') and apriori ('are there fictional, logical, mathematical entities?'). ${ }^{6}$ In both cases, the ontological question of whether, in the

\footnotetext{
${ }^{3}$ As is well known, Frege thought that, unlike simple, sentence-predicate, sentences, quantified sentences are of the form predicate-subject. This idea may well be questioned - cf. e.g. Bianchi-Napoli 2004.

${ }^{4}$ On this cf. e.g. van Inwagen 2008:37-8.

${ }^{5}$ In this I follow an already established tradition: cf. e.g. Priest $2008^{2}$. In the same vein, McGinn says that " $\exists$ " should be called not the existential, but the partial quantifier. Cf. 2000:32-7.

${ }^{6}$ Fine 2009 thinks that in the apriori case, sentences like 'ficta exist' have to be taken as not expressing particular, but rather a universal quantification also containing a first-order predication of existence ('all ficta exist'). Yet he acknowledges that
} 
overall domain of what there is, there are entities of a certain kind follows the metaphysical question of what would entities of that kind be, i.e., what nature they would have, provided that there were any. One can indeed address the second question without answering, either positively or negatively, the first question. ${ }^{7}$ Simply, in the aposteriori case one answers the ontological question by checking whether there are things of the relevant kind, while in the apriori case the answer must be provided by some sort of philosophical reasoning. For instance, an outward looking may help us in (negatively) settling whether there are unicorns, while an inward looking may help us in (positively) settling whether there are chimeras, yet neither an inward nor an outward looking can help us in settling whether there are ficta. We answer this question by putting forward ontological argument pro or contra such entities. One can even say that the answer in the apriori case is more fundamental than the answer in the aposteriori case, for a positive answer in the latter case ultimately rests on a positive answer in the former case. For instance, literally speaking we can truthfully aposteriori say that there are trees and tables, or fictional ducks and square roots, only once we have apriori settled that there are concrete individuals, or abstract entities, the metaphysical kinds to which the previous kinds respectively belong. ${ }^{8}$ In point of fact, we call a metaphysical kind a kind such that the question of whether it is instantiated is settled by a philosophical reasoning. For it is a kind regarding the nature of certain things (if there are any of them). All in all, for

in the aposteriori case, sometimes at least the 'particular quantifier'- reading is justified, e.g. when we say in physics 'There are electrons'. But if this is the case, how can he account for the case of mixed sentences whose first part is aposteriori while their second part is apriori, like 'although electrons exist, quarks don't' uttered say by a philosopher denying that there is a sub-subatomic layer of reality? If the first part the sentence contains a particular quantification, so should its second part, if we want to account for the anaphoric link occurring in it.

${ }^{7}$ For a clear distinction between the two questions, hence between the ontological and the metaphysical research enterprises, cf. e.g. Thomasson 1999.

${ }^{8}$ Pace Fine 2009, once the relevant apriori question were answered in the negative, it would only be make-believedly the case that there are the entities involved by the relevant aposteriori question. It is not the case that science makes us accept once for all that there are atoms or numbers and then philosophers merely debate on whether they are real or not, as Fine claims. We all say that there are sunsets. In this case we know that we are speaking loosely. Some philosophers claim that this precisely happens in a lot of other cases that we ordinarily take for granted. 
people believing in existence as the second-order property of being instantiated, Quine is perfectly right in claiming that to be is to be the value of a variable. For they would consider Quine's claim just as an alternative formulation of their own thesis.

Yet moreover, I also want to be committed to the first-order property of existence that is often mobilized in the traditional debate on existence. This is a substantive property, in the sense that for an individual to have it means to have a genuine attribute, a quality that really features that individual, or whose possession makes for that individual a difference - as it happens with all ordinary properties of individuals. ${ }^{9}$ Existence, thus, has to be ranked together with having a certain weight, being human, being Italian - just to give some examples. ${ }^{10}$ It is precisely this substantiality that has led many philosophers to find different candidates for what this property really amounts to. Echoing Plato (as well as the Stoics), some - e.g. Castañeda 1989 have taken existence to be being straightforwardly involved with causality, that is, being able both to provoke and to undergo effects. Some

${ }^{9}$ As is well known, Frege 1979 thought that there is no such property, for a singular existential sentence of the kind 'A exists' is tantamount to a quantified existential sentence of the kind ' $(\exists \mathrm{x})(\mathrm{x}=\mathrm{A})$ ', which is true insofar as the property of being identical with A has at least one instantiation; namely, A itself. However, I leave Frege's thought aside. For it is not clear how the quantified sentence has to be interpreted when it is false. For its interpretation seems to presuppose an object as the referent of the (possibly directly referential) singular term ' $\mathrm{A}$ ' which does not have to figure in the overall domain of what there is in order for the sentence to be false.

${ }^{10}$ In this respect, so-called relational Cambridge properties, like being a husband or being taller than Berlusconi (cf. Geach 1969), are substantive properties. For although their possession does not make a causal difference for an individual, it still makes a difference for that individual to have them. As we will immediately see, substantive properties are rather to be contrasted with formal properties, which can be Cambridge properties as well yet they do not make any difference at all for their bearers. Miller 2002 suggests that existence is a Cambridge property. For him, this shows why one can accept that singular existentials of the kind ' $\mathrm{N}$ exists' may be sometimes false and yet deny that existence is flanked by the complement property of nonexistence. Yet as I have just said, for a property to be a Cambridge one does not say too much insofar as there are two altogether different kinds of such properties, the substantive ones and the formal ones. Moreover, once first-order existence is splitted into both a (group of) substantive property(ies) and a formal one, unlike Miller one may stick to both the above claims: existence as a (group of) substantive property(ies) is not universal, existence as a formal property is such. 
others - e.g. Williamson 1990, 2002 - have rather taken existence to amount to having a spatiotemporal location. If there is no causality out of the spatio-temporal world, as many claim - e.g. Kim 2005 - these two candidates for existence collapse. Yet in a Meinongian framework this property may also be taken just as a species of existence tout courtamounting to what Meinong (1960) labelled Sein - which rather includes also another species, what Meinong again called subsistence. ${ }^{11}$ Subsistence can be meant as being not straightforwardly involved with causality, i.e., being able to provoke but not to undergo effects, or, in a possibly different formulation, having no spatio-temporal location. ${ }^{12}$ In the light of these further distinctions, it would be better to say that the substantive property amounts to a group of such properties whose extension varies. As existence tout court, existence for Meinongians applies to both concrete and abstract entities, while for those that make it collapse onto causality or spatio-temporality, it applies to concrete entities only.

One might take for granted - in fact, it has been taken for granted - that this first-order property is an existential one. For it may be enough to show that this property is typically mobilized in existential counterfactual reasoning, e.g. when I wonder how things would have been if I had not existed. ${ }^{13}$ Yet if this were merely the case, then this property would have nothing to do with the one typically expressed by the particular quantifier. Thus, existential discourse would be a merely ambiguous discourse - we would speak of existence sometimes to mean property instantiation, some other times to mean the substantive property(ies). But this is not the end of the matter. It is not accidental that we consider both properties as existential ones, for there is a relation between them. To see that this is the case, let me just introduce my third existential property. For we will see that the above relation also includes this third property.

\footnotetext{
${ }^{11}$ Sometimes Meinong flirted with the idea that subsistence is an intermediate species between existence and Sein: cf. e.g. 1960: 108. Moreover, in $1972^{2}$ he held that Sein is a special property of individuals, for it does not belong to the individuals' core. Yet for my present purposes I can leave these details of Meinong's doctrine aside.

${ }^{12}$ The latter formulation is closer to Meinong's intention; the former is due to Frege 1967: 211

${ }^{13}$ Cf. Evans 1982: 372.
} 
This further property is again a first-order property, a property of individuals. Yet unlike the previous one, it is a formal property: it makes no difference for an individual to have it. Russell $1937^{2}$ labelled it being, while Parsons 1980 and Williamson 2002 take it as existence in a logical sense. Its formality makes it universal: it does not divide the overall domain of individuals into two sub-domains, the domain of those individuals that possess it and the domain of those individuals that lack it, for it is possessed by all individuals. (As we will see later, the converse does not eo ipso hold: at least under certain ontological interpretations, an existential first-order property may be universal, and yet not be a formal property, but (one of) the substantive one $(\mathrm{s}).)^{14}$

This property can be naturally interpreted as the property of being identical with something, that precisely all individuals possess. ${ }^{15}$ Of course if it is so interpreted it entails the afore-mentioned secondorder property. For being identical with something is nothing but being such that there is something it is identical with it, i.e., $(\exists y)(x=y)$, or in other terms, being such that the property of being identical with it is instantiated. For some, moreover, the implication holds also in the opposite direction. ${ }^{16}$ One might thus say that the formal property collapses onto the second-order property. Yet first, one is not forced to this interpretation. One can also take that property as being an individual, a property that trivially all individuals possess. ${ }^{17}$ To be sure, even in such an interpretation one might say that any biconditional of the kind ' $\mathrm{N}$ formally exists iff there is something $\mathrm{N}$ is identical with it', where ' $\mathrm{N}$ ' is a genuine singular term, holds. Yet second, this would not make the two properties collapse either. For in the biconditional the order of explanation goes from right to left. It is

\footnotetext{
${ }^{14}$ In applying to an overall domain of individuals, this property is not universal in the sense in which, say, being trilateral applies to all triangles. For being trilateral is universal only in the restricted domain of triangles. To be sure, that there is an overall domain of individuals is a controversial issue. For an argument in favour of this idea, cf. famously Williamson 2003.

${ }^{15}$ Cf. e.g. Salmon 1987: 64-65, Williamson 2002.

${ }^{16}$ Cf. van Inwagen 2008: 58.

${ }^{17}$ Cf. Berto 2010. For other people allowing for such property, cf. e.g. Kroon 2004: 17, Lycan 2000: 19.
} 
because $\mathrm{N}$ formally exists (is an individual) that there is something $\mathrm{N}$ is identical with it. ${ }^{18}$

Now, why has this formal property to do with existential matters? Well, the answer to this question is also an answer to the question of what is the point of having introduced this property. Moreover, the same predicament holds of the other first-order property(ies) I previously introduced, the substantive one(s). In a nutshell, all such firstorder properties are existential for we need to rely on them to account for ontological debates that involve the second-order property. Insofar as we so need them, moreover, their postulation is justified. Let me explain.

\section{Why all these three properties are existential and we need all of them}

To start with, consider an ontologically exhaustive thesis - a thesis of the form 'There are only Fs' (or if you like its eliminativist counterpart 'There are no Gs, Hs, Is ...') - that is presented in philosophical reflections on ontology, on the issue of what entities we have to admit in the overall inventory of what there is. That thesis says (while its counterpart entails) that: i) the scope of the absolutely unrestricted particular quantifier coincides with the domain of the things that exist in a first-order sense; ii) these are the things of the metaphysical kind $F$ that is the most general, in the sense that there are no upper such kinds (the kind $G$, for instance) that are instantiated.

This already shows that in ontological debates we need not only the second-order property, but also a first-order property of existence. But what role does the latter property exactly play, and which of the two afore-mentioned first-order properties is here mobilized?

In order to answer these questions, consider how an ontologically exhaustive thesis is discussed in philosophical ontological debates. There is a longstanding discussion as to whether, when different

${ }^{18}$ On this point I utterly agree with Fine 2009, who interprets the first-order property in question as the property of being real. I am not sure, however, whether in Fine's approach the property in question is really a universal property. For he seems to admit that there are things of which it is true that they are not real. This seems to make him a sort of Meinongian. Granted, the fact that he does not ascribe particular quantification in general (a fortiori, on the overall domain) an ontological role diminishes this risk. 
philosophical parties have different opinions as to what the overall domain of what there is contains, those parties are simply talking past each other, in the sense that neither party really understands the thesis of its opponent but simply reframes it in its own terms, or there is real understanding between such parties. ${ }^{19}$ The second option is clearly more desirable than the first one; as Saint Anselm first envisaged as regards God, both realists and antirealists on Fs should understand what asserting that there are only Fs means. In point of fact, in order for one such ontological disagreement to be a genuine one, it must be a mere disagreement on the truth-value of the theses involved - the ontologically exhaustive thesis and its denial - which both parties understand in the same way. Now, such an understanding is precisely possible insofar as, although both parties understand the existential predicate mobilized in those theses as expressing a substantive first-order property of existence, for one party this property is universal, yet for the other party is non-universal. For this party, either a) there is another substantive property that is the universal one, or b) the universal property is not substantive at all. As a result, in order to completely understand the denial of the ontologically exhaustive thesis put forward by the party holding b), one has to assume that there is a formal first-order property over and above the substantive one. Thus, both our first-order properties are required in order for a philosophical ontological disagreement not simply to consist in two parties talking past each other. Moreover, the way such properties are involved in that debate shows that both of them are really existential properties. For they are ontologically relevant in helping one to decide what there really is in the general inventory; namely, by settling which is the most general metaphysical kind which has the further second-order existential property of being instantiated.

Let me just give some connected examples of what I have in mind. First of all, consider an ontological debate between physicalists and non-physicalists. Physicalists say, there are only things that physically exist. Non-physicalists deny that, for them there are also things that do not physically exist. Clearly enough, in order for the two parties to understand each other, it must be the case that in the physicalist claim as well as in the non-physicalist denial of its, the first-order

\footnotetext{
${ }^{19}$ A famous example of this predicament is in Lewis 1990.
} 
property of spatio-temporal existence, a substantive first-order property, is mobilized. What the two parties disagree on is the truth-value of their respective thesis. For, in believing their claim to be true, physicalists hold that that very substantive property is universal, i.e., that it applies to all individuals. While in disbelieving that claim to be true, non-physicalists assume that that property is not universal, i.e., that it applies to some individuals - the physical things - but it does not apply to others. Possibly, moreover, they assume that the universal property is another substantive first-order property - Platonic nonphysicalists indeed hold that there are only things existing à la Meinong, i.e., both spatio-temporal and non-spatiotemporal items. (Incidentally, it has sounded obvious to call the particular quantifier the existential quantifier precisely because Platonic non-physicalism has become the received view. For according to Platonic nonphysicalists, in its absolutely non-restricted use the quantifier bounds variables ranging on tout court existents only.)

Now, Quineans - who stick not only to physical things, but also to some mathematical entities like sets - are precisely a sort of Platonic non-physicalists. They say that there are only tout court existing things, in Meinong's sense. But Meinongians deny that; as Meinong himself (1960:83-5) originally claimed, there are things of which it is true that there are no such things, i.e., that they do not exist (in the above sense). Meinong said that this claim was only apparently paradoxical. Many Quineans say that it is really such. For them it indeed is contradictory: how can one can say that there exist things that do not exist? ${ }^{20}$ Now, if we do not want the two parties to talk past each other, we have to suitably reconstruct their debate. Both Quineans and Meinongians understand their opposite claims as involving the substantive first-order property of existence tout court. Yet Quineans hold that this property is universal, while Meinongians hold that it is not such. This is why the Quinean claim is true for the Quineans but false for the Meinongians. Moreover, the Meinongians' conviction that their denial of the Quinean claim is correct is well-grounded. For them, the first-order property that so to speak fixes the extension of the overall domain is no substantive first-order property, but rather the formal one. In other terms, the Meinongians' commitment to the formal first-order property is required in order to understand their

${ }^{20}$ Cf. e.g. Lycan 1979: 290, Salmon 1982: 39 n. 41. 
denial of the Quinean claim that there are only tout court existing things. For Meinongians, there are also things that do not exist tout court. For according to them, all the things that there are in the overall domain are things that formally exist. Put alternatively, a Meinongian cannot formulate his own point of view in terms of an ontologically exhaustive thesis ('there are only Fs'), precisely for she sticks to the idea that the first-order existential property fixing the scope of the overall domain is universal because it is formal. ${ }^{21}$

On behalf of the Quinean, one might reply in this way. There is a way both for Quineans and Meinongians to utterly agree not only on the meaning, but also on the truth-value, of the thesis 'There are only things that exist', if 'exist' here meant the formal first-order property. In point of fact, this is what Quine seems to have in mind when he answers the question 'What there is?' simply by saying 'Everything' (1952:189); who might disagree on that, which is a mere truism?22 Yet, Quine would surely go on saying, my everything is not the everything of my Meinongian interlocutor. How to account for this fact? Well, there indeed is a disagreement between the two parties,

\footnotetext{
${ }^{21}$ Meinong denied that both the things that exist tout court and the things that do not exist tout court share a further existential property. Yet, as van Inwagen 2008: 39 has correctly noticed, this would make his thesis really contradictory. How could it be that there are things of which it is true that there are no such things? To be sure, Meinong's rejection merely depended on the fact that he was worried that in allowing for one such property, he would have allowed for things as such to possess a quasi-existence, as he said: cf. 1960: 84-85. Yet formal existence is no quasi-existence, if 'quasi-existence' means a sort of substantive existence; formal existence is no substantive existence at all. Moreover, as I said, it plays an existential role insofar as it fixes the extension of the overall domain of what there is.

${ }^{22}$ Van Inwagen 2008: 38 precisely claims that in a mutually understood ontological exhaustive thesis, the first-order existence predicate involved means what I have taken to be the formal property of existence. As a result, he cannot understand why Meinongians hold that the thesis is false. (Lewis 1990: 29-30 actually made a similar point: Quineans and Meinongians can agree on what there is only if the scope of the absolutely unrestricted quantifier is fixed by the formal property of existence; yet Meinongians also want to use it restrictedly by mysteriously appealing to existence itself.) Now definitely, if the property involved in the thesis were the formal property, the Meinongian could not deny that thesis; at most, she would see it as vacuous. Yet she denies it for she takes it as involving the substantive property, so that she can reasonably deny its universality. Moreover, van Inwagen himself needs the substantive property, in order for the ontological thesis to become informative (see below).
} 
the Quinean and the Meinongian; yet what this disagreement really amounts to is that while the Quineans further hold that the formal first-order property is co-extensive with the substantive property of existence tout court, according to the Meinongians those two properties are not co-extensive, for their substantive property is not universal at all.

Yet if this were the case, the ontological claim on what there is would never be an informative thesis. But this is not the case. For the ontological debate consists in someone advancing an ontologically exhaustive thesis - there are only Fs - which her interlocutor precisely denies. In other terms, 'only' cannot work in such a thesis as a wheel that turns idly, as Wittgenstein would have put it; it conveys a genuine information - by saying that there are only Fs, one precisely denies that there are Gs, Hs, Is $\ldots .{ }^{23}$ In order for the Quinean to hold something informative, she should not only hold (the truism) that things that formally exist are what there are, but also that things that formally exist are all and only the things that substantively exist. But this again shows that all our existential properties have to be mobilized in order for a philosophical ontological disagreement to be intelligible.

Here examples might be multiplied at will (for instance, one would have to appeal to the above first-order properties, namely, to one of the substantive ones and to the formal one, in order to understand the dialectic involved in the debate between actualism and possibilism, or the dialectic involved in the debate between possibilism and impossibilism) but I think the point is clear. A philosophical ontological debate on what there is first of all involves the secondorder property of existence, by focussing the discussion on which is the most general metaphysical kind to be instantiated. Yet in order to assure full understanding of the contrasting theses occurring in such debate, both the formal and (one of) the substantive property(ies) of existence must be involved as well. For in order for those theses to be not only understandable but also informative, those properties have to be ultimately involved in order for either party to know how the

\footnotetext{
${ }^{23}$ Pace Wittgenstein 1975: $§ 69$, however, an ontologically exhaustive thesis remains informative even if it is taken to be necessarily true. For, although it is not and it could have not been the case that there are Gs, Hs, Is, the thesis that necessarily there are only Fs remains informative insofar as it rules out that there might have been Gs, Hs, Is.
} 
other party conceives that the overall domain of what there is to be basically delimited. Moreover, although those properties are different both from one another and from the second-order property as well, they are perfectly legitimated in their being considered existential properties. For they are mobilized precisely in the role of fixing the boundaries of the overall domain.

\section{Why the Meinongian ontological option is better than the others}

Up to now, I have remained neutral as to which philosophical ontological claim on what there is has to be recommended. In this Section, I would like to put forward some arguments in favour of the Meinongian option, according to which the substantive first-order property(ies) of existence is (are) non-universal. To begin with, holding that such property(ies) is (are) non-universal enables one to mobilize them in order to perform a contextual restriction of the particular quantifier. As is well-known, in non-philosophical discourse such quantifier often occurs contextually restricted; when somebody asks us if there is beer and we reply positively, we do not mean that there is beer in the overall domain, bur rather that there is beer in the house, if not merely in the house's kitchen, or even simply in the kitchen's fridge. Now, the same may well happen in philosophical discourse; thus, a quantified sentence saying that there are entities of a kind $F$ may well be true or false depending on which domain is chosen to make the variables bound by the particular quantifier range on it. Moreover, in such a case the contextual restriction of the quantifier is made precisely by appealing to (one of) the substantive property(ies). ${ }^{24}$

Let me just make some examples. For a Meinongian believing that ficta are abstract entities, ${ }^{25}$ the ontologically affirmative sentence:

${ }^{24}$ Incidentally, this is why it is better to say that there is a group of such properties rather than saying, along with Predelli 2002, that there is just one such property that is typically expressed by the first-order predicate of existence which however occurs restricted in different ways according to the different contexts of use of the sentence involved.

${ }^{25}$ Voltolini 2006 is one such example. Zalta 1983 is not exactly one such example, for he believes that the overall domain of what there is shrinks to the existents tout court. In this respect, he is a Platonic Meinongian rather than a genuine Meinongian. 
(1) There are fictional objects

is true if the quantifier occurs absolutely unrestricted; it is still true if the quantifier occurs restricted to the existents tout court, the things which are either abstract or concrete; yet it is false if the quantifier occurs restricted to the spatiotemporal existents. As I said, such restrictions are operated by mobilizing different substantive first-order properties; in the first case, it is as if we had (truly) said that there are things that exist tout court and they are fictional, while in the second case it is as if we had (falsely) said that there are things that spatiotemporally exist and they are fictional.

Now, consider the ontologically negative quantified sentence:

(2) There are no numbers.

For a Meinongian, this sentence is false if the quantifier occurs absolutely unrestricted, again false if the quantifier occurs restricted to the existents tout court - they include abstracta, hence they include numbers - yet true if the quantifier occurs restricted to the spatiotemporal existents, which merely include concreta.

As a second advantage, the Meinongian option allows us to properly account for existential comparisons between individuals, either singularly designated (i.e., by means of directly referential singular terms) or generically described (i.e., by means of either indirectly referential singular terms or mere nominal syntagms).

Consider for instance the following sentences:

(3) Unlike contemporary Danish citizens, all the characters in Hamlet do not exist

(4) Unlike Charles, Hamlet does not exist

(5) Obama exists, but Santa and the round square do not.

All these sentences are true only if in them 'to exist' means spatiotemporal existence. Now take:

(6) Unlike the circle, both the roundabout down there and the round square do not exist. 
This sentence is true only if in it 'to exist' means subsistence. Finally, consider:

(7) Unlike Obama and Santa, the round square does not exist.

This sentence is true only if in it 'to exist' means existence tout court.

Since those sentences both contain anaphoric relations and mix directly referential devices with indirectly referential devices, it would be hard to endorse either an utterly traditional descriptivist reading of them, in which all proper names work as disguised definite descriptions, or a partially traditional descriptivist reading of them, in which only purportedly empty proper names work as such. For in the first case, we would have to implausibly deny that full proper names names having a designatum - are directly referential devices; in the second case, we would not be able to account for the anaphoric relations in the involved sentences.

By way of illustration, let us accept for argument's sake Quine's (1952) proposal that any proper name instantiating a morphosyntactically simple kind $N$ is synonymous with an ad hoc description of the kind the $\mathrm{N}$-er. ${ }^{26}$ A traditional descriptivist paraphrase e.g. of (4) would thus sound as follows:

(4TD) There is a unique charlesizer yet there is no unique hamletizer.

Yet if 'Charles' is a full proper name designating Prince Charles of Wales and Kripkeans are right as to its being a directly referential device, i.e., to its exhausting its truth-conditional contribution in its having a certain referent, then the first conjunct of (4) cannot be so paraphrased. 'Charles' directly refers to Prince Charles, 'exists'

\footnotetext{
${ }^{26}$ But just for argument's sake. For this proposal entails taking a singular negative existential of the form 'O does not exist' as tantamount to 'There is no unique O-er', whose truth cannot be easily accounted for if it is intended to rule out that there is such a thing as the $\mathrm{O}$-er in the overall domain. If this were indeed the case, how could the predicate of the form 'to be a O-er' be meaningful, as it precisely seems to presuppose that such a thing belongs to that domain since it contains a genuine singular term of the form ' $\mathrm{O}$ ' as referring to that thing? For this problem cf. Leonardi-Napoli 1990.
} 
expresses a first-order property that is true of him; most naturally, the substantive property of spatio-temporal existence, as I said before.

On behalf of the Russellean, one might reply that only the purportedly empty proper names have to be so paraphrased, so as to comply with a partial traditional descriptivism. Thus, (4) would rather have to be replaced by:

(4PTD) Charles exists yet there is no unique hamletizer.

Yet such a reading breaks the anaphora (4) contains. To be sure, there may well be cases in which anaphoric relations do not require sameness of meaning, as in:

(8) Madonna likes to listen to herself

in which 'Madonna' refers to the famous pop singer yet the reflexive pronoun 'herself' refers not to Madonna, but to some CD of hers. ${ }^{27}$ But no such case can be envisaged here. Unlike (8), there is no pragmatic relation between the meanings here involved that justifies such a meaning shift. ${ }^{28}$ Moreover, consider (7). It cannot be the case that (7) is paraphrased as:

(7PTD) Obama exists, yet there is neither a unique santasizer nor a unique round square.

For whatever is the meaning of 'exist' in the second part of (7), the meaning in its first part must remain the same as predicated both of 'Obama' and of 'Santa'. In other terms, (7PTD) does not account for the meaning (7) conveys, according to which the negative comparison is made between the round square on the one hand and both Obama and Santa on the other.

As a final rejoinder, the Russellean might say, 'but look! If you accept a Russellean analysis of both definite and indefinite descriptions,

${ }^{27}$ For such cases, cf. originally Fauconnier 1985. See on this also Sainsbury 2010: 139 .

${ }^{28}$ This is why a sentence like 'Obama exists, yet N.N. does not' would be infelicitous, if 'N.N.' were an utterly empty name so that 'N.N. does not exist' would be forced to mean, à la Frege $1980^{3}$ b, “'N.N.” does not refer'. I cannot unfortunately expand here on this. 
the sentences you present show that you are exactly running in the same troubles. You have to admit that in (7) "exists" stands for a firstorder property with respect to both "Obama" and "Santa", but for a second-order property with respect to "the round square", so that you also do not account for anaphora. Moreover, you have to admit that in (5) "exist" must mean the same with respect to both "the round square" and "Santa", so you have to allow for a descriptive analysis of purportedly empty proper names.'

But to endorse a Russellean analysis of definite descriptions does not at all imply that whenever the predicate 'to exist' occurs in a sentence containing a definite description, it has to be meant as expressing the second-order property, i.e., as being the particular quantifier in disguise. One would be forced to hold this if one said, as in the traditional Russellean analysis, that the relevant existential sentences mobilize only one existential property, the second-order one. But once we have more existential properties at our disposal, we can mobilize them to account not only for sentences containing directly referential devices, but also for sentences containing indirectly referential devices, while still sticking to an (admittedly nontraditional) Russellian analysis of definite descriptions. So, in my perspective (5) has to be accounted for in this (non-traditional) Russellean way:

(5NTD) Obama exists, yet Santa does not, and there is a unique round square that does not exist as well

where 'exist' means spatio-temporal existence throughout the sentence, while (7) becomes:

(7NTD) Obama and Santa exist, yet there is a unique round square that does not exist

where 'exist' means existence tout court throughout the sentence. I leave to the reader how to properly paraphrase (3) and (6). ${ }^{29}$

And now, a bit of fireworks. There is a final, and perhaps the most relevant, advantage of committing to all such existential properties, in

${ }^{29}$ Lycan 2000: 19 provides one similar analysis of existentials involving definite descriptions. Yet by the verb 'to exist' figuring in such sentences Lycan means what I have called the formal first-order property. 
particular to both the second-order one and to the substantive firstorder one(s). This commitment shows why, although the ontological argument is valid, it cannot prove what it should prove.

Consider the following theoretical reconstruction of the ontological argument as an ex absurdo argument: ${ }^{30}$

a) The perfect being does not exist

b) The perfect being is the entity of which nothing greater may be thought [def.]

c) If the perfect being does not exist, then something greater may be thought of

d) Something greater than the perfect being may be thought of [from a),

c)]

e) Contradiction [b),d)]

f) Hence, the perfect being does exist.

Doubtlessly, the argument is valid. Yet paradoxically enough it proves nothing ontologically relevant, namely, that there is such an unique thing as a perfect being. As I have said, an ontological question regards what there is in the overall ontological inventory; thus, it mobilizes the second-order property of existence. So, if there were a genuine ontological argument, it should prove that there is an unique perfect being. Yet our argument proves something metaphysically relevant; namely, as I said before, something concerning the nature of an entity (of a certain kind) provided that there is any. Namely, it proves that, if there is an unique perfect being, then it exists in the first-order substantive sense; in other terms, it proves that substantive existence belongs to the nature of an unique perfect being. Or in another different formulation, it proves that, provided that there were any, an unique perfect being cannot fail to substantively exists, for otherwise it would not be perfect. As one can easily see, this piece of reasoning mobilizes both the second-order property and a substantive first-order property. ${ }^{31}$

\footnotetext{
${ }^{30}$ I do not definitely claim that Saint Anselm had in mind this version of the argument, although his talk of existence as perfection makes hard to deny that for him existence worked as a first-order property.

${ }^{31}$ One might wonder why the argument does not mobilize the formal firstorder property. The reason is simple. Whatever it proves, we don't want the argument to be straightforwardly trivial. Since as I said the formal property is
} 
Why speaking of existence properties rather than existence predicates

Before ending, let me add just some methodological remarks. In this paper, I have always spoken of existence properties rather than of existence predicates. Clearly, this sounds controversial. As I already pointed out at the beginning of this paper, many would not accept e.g. that by endorsing second-order existential claims one also commits to a second-order existential property. Moreover, parallel doubts may arise with respect to first-order existential claims.

Yet there is a reason as to why I have preferred standing on the side of reality rather than on the side of language. As far as natural language is concerned, existential claims are unbearably obscure. For existential predicates occurring in them are irremediably ambiguous between a first-order usage (or more than one as we have seen) and a second-order usage. So, it is not the case that we can rely on a linguistic distinction between an allegedly second-order predicate such as 'there is' and allegedly first-order predicate such as 'to exist' in order to single out the corresponding existential properties. For either predicates can be used both ways. On the one hand, for instance, in Italian one says:

(9) Dio c'è [there is such a thing as God].

This sentence involves a 'there is'- locution. Yet clearly enough, it is normally used to mean something stronger than that God also figures in the overall inventory of what there is; namely, that God substantively exists. As we saw before, it would be a relevant ontological discovery if in the overall domain there were a unique perfect being. Yet nobody would be moved by the fact that some entity of other named 'God' were included in an inventory which, if we are Meinongians, also includes possible golden mountains and impossible round squares. One would be rather moved by the fact that, in such an inventory, God figures as a substantively existent item, namely as something that may interact with us. (Incidentally, this is why the ontological argument as reconstructed before may still strike us at sense that it is identical with something or that it is an individual. 
least from a metaphysical point of view. For it says that it is not a matter of faith but an apriori truth that, if there is an unique perfect being in that inventory, then that being substantively exists.) On the other hand, 'to exist' does not infallibly mean a first-order property. Consider a sentence like:

(10) Platypuses exist

which many British naturalists uttered when they arrived in Australia at the end of the $19^{\text {th }}$ century. In (10), 'exist' expresses particular quantification, what would be more naturally expressed by:

(10Q) There are such things as platypuses.

On behalf of the linguistic approach to existence, one might reply that in natural language one can always tell a use of 'there is' for particular quantification, hence to express a second-order property of existence, from a use of 'to exist' expressing a first-order property. In point of fact, when one says 'there exists ...', one is using the quantifier as contextually restricted to the substantively existing things. ${ }^{32}$ This nicely fits with the idea, that I myself endorsed before in writing down a theoretical reconstruction of the ontological argument, that when we say things like 'the F exists', 'to exist' captures the substantive firstorder property. ${ }^{33}$

Yet I am unclear as to whether sentences of the form 'The F/ a F / F exists' always have such existential reading. First of all, if instead of uttering (10) I said:

(11) Chimeras exist

\footnotetext{
${ }^{32}$ In his 2005, Priest is even more radical than that. He claims that first, in English at least 'there is' always means 'there exists' as a quantifier contextually restricted to substantively existents, and second, if in English we want to express particular (i.e., non-existentially loaded) quantification, we have to use the indefinite pronoun 'some'. (For a similar point cf. also McGinn 2000).

${ }^{33}$ For all this see Moltmann 2012a,b. To be sure, Moltmann is also ready to read a definite description figuring in an existential claim as standing nonRusselleanly for an abstract entity, something like a role for instance.
} 
I would not mean that there are things that are chimeras in the subdomain of the substantively existing things, for I know that chimeras do not exist in that sense. Rather, by (11) I simply limit myself to saying that chimeras belong to the overall domain of what there is, as non-substantively existing items (perhaps as possible entities, or even as impossible ones). Moreover, even if we could happily tell a quantificational use of the 'there is'- locution from a first-order predicative use of the 'to exist'- locution, 'to exist' would still be ambiguous between its expressing a substantive first-order property of existence and its expressing the formal first-order property. This is why, even if we allow 'to exist' a mere first-order predicative use, a sentence such as:

(12) If the perfect being exists, then it exists

would remains informative, or at least not straightforwardly trivial. For in (12)'s antecedent, 'exists' means the formal property, so that that antecedent may be seen as saying that there is a unique perfect being and this individual formally exists. Yet in (12)'s consequent, 'exists' means (one of) the substantive property(ies).

\author{
Alberto Voltolini \\ University of Turin \\ Department of Philosophy and Education Sciences \\ I-10124 - Turin, Italy \\ alberto.voltolini@unito.it
}

\title{
References
}

Berto, Francesco. 2010. L'esistenza non è logica. Roma-Bari: Laterza.

Bianchi, Andrea \& Napoli, Ernesto. 2004. Poche parole. In Filosofia e logica, edited by M. Carrara \& P. Giaretta, Soveria Mannelli: Rubbettino: 175-225.

Castañeda, Hector-Neri. 1989. Thinking, Language, and Experience. Minneapolis: University of Minnesota Press.

Evans, Gareth. 1982. The Varieties of Reference. Oxford: Clarendon Press.

Fauconnier, Gilles. 1985. Mental Spaces. Cambridge: Cambridge University Press.

Fine, Kit. 2009. The Question of Ontology. In Metametaphysics: New Essays on the Foundations of Ontology, edited by D.J. Chalmers, D. Manley, and R. Wasserman, Oxford: Oxford University Press: 157-177. 
Frege, Gottlob. 1967. Le nombre entier. In Kleine Schriften. Hildesheim: G. Olms: 211-219.

Frege, Gottlob. 1974². The Foundations of Arithmetic. Oxford: Blackwell.

Frege, Gottlob. 1979. Dialogue with Punjer on Existence. In Posthumous Writings, edited by H. Hermes, F. Kambartel, and F. Kaulbach, Chicago: The University of Chicago Press: 65-67.

Frege, Gottlob. 19803a. Concept and Object. In Translations from the Philosophical Writings of Gottlob Frege, edited by P. Geach and M. Black, Oxford: Blackwell: 42-55.

Frege, Gottlob. $1980^{3} \mathrm{~b}$. On Sense and Denotation. In Translations from the Philosophical Writings of Gottlob Frege, edited by P. Geach and M. Black, Oxford: Blackwell: 56-78.

Geach, Peter T. 1968. What Actually Exists. Proceedings of the Aristotelian Society 42: 7-16.

Geach, Peter T. 1969. God and the Soul. London: Routledge \& Kegan Paul.

Hintikka, Jaakko. 1986. Kant, Existence, Predication and the Ontological Argument. In The Logic of Being, edited by S. Knuttila and. J. Hintikka, Dordrecht: Reidel: $249-268$

Kim, Jaegwon. 2005. Physicalism, or Something Near Enough. Princeton: Princeton University Press.

Kroon, Frederick. 2004. Descriptivism, Pretense, and the Frege-Russell Problems. The Philosophical Review 113: 1-30.

Leonardi, Paolo \& Napoli, Ernesto. 1990. On Naming. In On Quine, edited by P. Leonardi and M. Santambrogio, Cambridge: Cambridge University Press: 251 266.

Lewis, David. 1990. Noneism or Allism? Mind 99: 23-31.

Lycan, William. 1979. The Trouble With Possible Worlds. In The Possible and the Actual, edited by M.J. Loux, Ithaca: Cornell University Press: 274-316.

Lycan, William. 2000. Philosophy of Language. London: Routledge.

Makin, Gideon. 2000. The Metaphysicians of Meaning. London: Routledge.

McGinn, Colin. 2000. Logical Properties. Oxford: Clarendon Press.

Meinong, Alexius. 1960. On the Theory of Objects. In Realism and the Background of Phenomenology, edited by R. Chisholm, New York: Free Press: 76-117.

Meinong, Alexius. 1972². Über Möglichkeit und Wahrscheinlichkeit. In Gesamtausgabe bd. VI, Graz: Akademische Druck- und Verlagsanstalt.

Miller, Barry. 2002. Existence. The Stanford Encyclopedia of Philosophy, edited by E.N. Zalta, URL $=<$ http://plato.stanford.edu/entries/existence/ $>$.

Moltmann, Friedericke. 2011a. Abstract Objects and the Semantics of Natural Language. Oxford: Oxford University Press. 
Moltmann, Friedericke. 2011b. Intentional Objects as Abstraction from Referential Acts. Unpublished MS.

Parsons, Terence. 1980. Nonexistent Objects. New Haven: Yale University Press.

Predelli, Stefano. 2002. 'Holmes' and Holmes. A Millian Analysis of Names from Fiction. Dialectica 56: 261-279.

Priest, Graham. 2008². An Introduction to Non-Classical Logic. Cambridge: Cambridge University Press.

Quine, Willard Van Orman. 1952. On What There Is. In Semantics and the Philosophy of Language, edited by L. Linsky, Urbana: University of Illinois Press: 189-206.

Rapaport, William J. 1978. Meinongian Theories and a Russellian Paradox. Noûs 12: 153-180.

Routley, Richard. 1980. Exploring Meinong's Jungle and Beyond. Canberra: Australian National University.

Russell, Bertrand. 1905. On Denoting. Mind 14: 473-493.

Russell, Bertrand. 1937². The Principles of Mathematics. Cambridge: Cambridge University Press.

Sainsbury, Mark. 2010. Fiction and Fictionalism. London: Routledge.

Salmon, Nathan. 1982. Reference and Essence. Oxford: Blackwell.

Salmon, Nathan. 1987. Existence. Philosophical Perspectives 1: 49-108.

Schiffer, Stephen. 2003. The Things We Mean. Oxford: Clarendon Press.

Sluga, Hans D. 1980. Gottlob Frege. London: Routledge \& Kegan Paul.

Thomasson, Amie L. 1999. Fiction and Metaphysics. Cambridge: Cambridge University Press.

Van Inwagen, Peter. 2008. Mc Ginn on Existence. The Philosophical Quarterly 58: 36-58.

Voltolini, Alberto. 2006. How Ficta Follow Fiction. A Syncretistic Account of Fictional Entities. Dordrecht: Springer.

Williams, Christopher J.F. 1992. Being, Identity, and Truth. Oxford: Oxford University Press.

Williamson, Timothy. 1990. Necessary Identity and Necessary Existence. In Wittgenstein: Towards a Re-Evaluation I, edited by R. Haller and J. Brandl, Vienna: Hölder-Pichler-Tempsky: 168-175.

Williamson, Timothy. 2002. Necessary Existents. In Logic, Thought and Language, edited by A. O' Hear, Cambridge: Cambridge University Press, 233-251.

Williamson, Timothy. 2003. Everything. Philosophical Perspectives 17: 415-465.

Wittgenstein, Ludwig. 1975. Philosophical Remarks. Oxford: Blackwell.

Zalta, E.N. 1983. Abstract Objects. Dordrecht: Reidel. 